\title{
Efficacy of an Hypericum Perforatum (St. John's Wort) Extract in Preventing and Reverting a Condition of Escape Deficit in Rats
}

\author{
Carla Gambarana, M.D., Ombretta Ghiglieri, Ph.D., Pierluigi Tolu, Ph.D., \\ M. Graziella De Montis, Ph.D., Daniela Giachetti, Ph.D., Ezio Bombardelli, Ph.D., \\ and Alessandro Tagliamonte, M.D.
}

The treatment of unselected depressed patients with an hydro-alcoholic extract of Hypericum perforatum has been reported to have an efficacy similar to that of classical antidepressants. In the present report, the effects of $\mathrm{H}$. perforatum were studied on three animal models of depression: (i) an acute form of escape deficit (ED) induced by an unavoidable stress; (ii) a chronic model of ED, which can be maintained by the administration of mild stressors on alternate days; (iii) a model of anhedonia based on the finding that repeated stressors prevent the development of an appetitive behavior induced by vanilla sugar in satiated rats fed ad libitum. H. perforatum acutely protected animals from the sequelae of unavoidable stress; such an effect was partially prevented by the administration of SCH 23390 or (-)-pindolol. Moreover, $\mathrm{H}$. perforatum reverted the ED maintained by repeated stressors and preserved the animal's capacity to learn to operate for earning a positive reinforcer. It was concluded that $\mathrm{H}$. perforatum contains some active principle(s) endowed with antidepressant activity.

[Neuropsychopharmacology 21:247-257, 1999]

(C) 1999 American College of Neuropsychopharmacology.

Published by Elsevier Science Inc.
KEY WORDS: Anhedonia; Depression; Escape deficit; Fluoxetine; Hypericum perforatum; Imipramine; Rat

Hypericum perforatum is an herbaceous perennial plant belonging to the Hypericaceae family. It is a small shrub with yellow flowers, poisonous to livestock, widely distributed in Europe, Asia and Northern Africa and naturalized in the U.S.A. H. perforatum, known as St. John's wort in the Anglo-Saxon culture, is wellknown in folk medicine. It has been used since Greek

From the Institute of Clinica delle Malattie Nervose e Mentali, Pharmacology Unit (CG, OG, PT, MGDM, AT), and the Institute of General Biology (DG), University of Siena, Siena, Italy; and INDENA, S.p.A., Scientific Department (EB), Milan, Italy

Address correspondence to: Carla Gambarana, Institute of Clinica delle Malattie Nervose e Mentali, Pharmacology Unit, Via Aldo Moro, 4, 53100 Siena, Italy.

Received September 28, 1998; revised February 22, 1999; accepted February 25, 1999. and Roman times in a wide spectrum of clinical applications including wound healing, anti-inflammatory and antiseptic activity, treatment of sleep and anxiety disorders, and mental depression [described by Dioscorides (1st century, A.D.), Galen (2nd century, A.D.), Pliny (book XXIV of his "Historiarum mundi", Paracelsus in the Middle Age), Mattioli in its "Discorsi" in the Renaissance; see also Duke 1985]. H. perforatum extracts contain numerous constituents belonging to different chemical classes and this may explain their various alleged therapeutic indications. The dry hydroalcoholic extracts of $H$. perforatum available in Europe are prepared from the upper aerial parts of the plant and the content of the components varies with the harvesting period, as well as with drying and storage conditions. These extracts contain six major groups of molecules: naphtodianthrones, acylphloroglucinols, flavonol glycosides, biflavones, proanthocyanidines, and phenyl- 
propanes. However, the better known components isolated from different parts of the plant are the dianthronic and anthranolic constituents such as hypericin, a naphthodianthron on which most of the available preparations are standardized. Another molecule which appears to be relevant to $H$. perforatum central activity is hyperforin, an acylphloroglucinol derivative (Erdelmeier 1998). A thorough description of $H$. perforatum constituents has been recently reported (Bombardelli and Morazzoni 1995).

Today this medicinal plant is used in several countries for the treatment of mental depression, and it is sometimes referred to as "herbal Prozac". Different preparations of $H$. perforatum have been reported as efficacious antidepressant medications in Germany during the last ten years (De Smet and Nolen 1996). Two metaanalysis of numerous clinical trials on the antidepressant efficacy of $H$. perforatum extracts have been published recently (Ernst 1995; Linde et al. 1996). They only included trials which were carried out according to criteria such as randomization, double blind against another antidepressant or placebo, and selection of patients and outcomemeasures. The general conclusion was that, notwithstanding the differences in the composition of the preparations used, $H$. perforatum appeared to be more effective than the placebo in treating some depressive disorders. However, it is not yet known whether $H$. perforatum is more efficacious in certain forms of depression than others, and whether it is active in major depression. The plant extract has been reported to have fewer side effects than classical antidepressants, but the duration of the trials was generally too brief to provide conclusions on its actual toxicity. Although several studies have investigated the possible mechanism of action of the antidepressant activity of $H$. perforatum extracts (Müller et al. 1997, 1998; Nahrstedt and Butterweck 1997; Chatterjee et al. 1998; Laakmann et al. 1998), no conclusive evidences on such activity have been reported either in humans or in animal models. Thus, we decided to assess the activity of a total extract of $H$. perforatum in three experimental models recently devised in our laboratory for the study of antidepressant treatments (Gambarana et al. 1995a, De Montis et al. 1995, Ghiglieri et al. 1997).

Our depression paradigms are based on the modified reactivity of rats to external stimuli induced by unavoidable stress. The first model is an acute form of escape deficit (ED), the utilization of which is restricted to the evaluation of the protective activity of antidepressants on the behavioral sequelae of an unavoidable stress (Gambarana et al. 1995a). The second is a chronic model of ED, which can be maintained indefinitely by the administration of tedious, mild stressors on alternate days (De Montis et al. 1995), and which allows the study of ED reversal by antidepressant treatments (De Montis et al. 1995). The third is a model of anhedonia based on the finding that repeated unavoidable stressors prevent the development of an operant appetitive behavior induced and maintained by a highly palatable food (vanilla sugar) in rats fed ad libitum (Ghiglieri et al. 1997). Imipramine or fluoxetine given daily for two weeks before and also during the training phase completely protect animals from the effects of chronic stress (Ghiglieri et al. 1997). The purpose of the present study was to establish whether $H$. perforatum was effective in the previously described animal behavioral tests that have been validated to evaluate antidepressant efficacy. Once the efficacy of the extract were established in these models, studies could then be conducted to evaluate active components of the extract and the neuropharmacological mechanisms that might be responsible for its behavioral effects.

\section{METHOD}

\section{Animals}

Experiments were carried out on male Sprague-Dawley rats (Charles River, Calco, Italy) weighing initially 125$150 \mathrm{~g}$. Animals were housed five per cage and kept in a controlled environment maintained at a constant temperature and humidity on a $12 \mathrm{hr}$ inverted light/dark cycle (7:00 a.m. lights off, 7 p.m. lights on), with free access to food and water. All rats were allowed at least one week of habituation to the animal colony before any treatment began.

The procedures used in this study were in strict accordance with the European legislation (EEC n. 86/609) and with the guidelines of the National Institutes of Health on the use and care of laboratory animals.

\section{Antinociceptive Tests}

The purpose of these experiments was that of evaluating a possible analgesic activity of $H$. perforatum, the existence of which would constitute a major bias in evaluating a reduction or lack of behavioral sequelae to a noxious stimulus. Pain threshold was assessed by the radiant heat tail-flick method according to D'Amour and Smith (1941) and by the hot-plate method (Woolfe and McDonald 1944; Eddy and Leimbach 1953). For the tail-flick test, the animals were taken into the test room, placed on the tail-flick apparatus (Socrel model DS 20), held gently by the experimenter with their tails smoothed into the tail groove. The radiant heat intensity was adjusted to obtain average latency values of about 6 sec. A 12 sec cut-off point was employed to prevent tissue damage to the tail. For the hot plate test, animals previously habituated to the apparatus, were individually placed on the hot-plate $\left(55^{\circ} \mathrm{C}\right)$ and their latency to paw licking was recorded. A 20-second cut-off point was employed to prevent tissue damage. For both tests 
the mean of 5- 6 base-line values assessed before treatment was compared to the mean values obtained 1 and $2 \mathrm{hr}$ following treatment.

\section{ED Induction}

Acute Stress Procedure. The ED paradigm is a slight modification of the classical Learned Helplessness Syndrome which has already been described (De Montis et al. 1995; Gambarana et al. 1995a). In brief, the unavoidable shock session lasted $50 \mathrm{~min}$. Each rat was completely immobilized by a flexible wire-net; the distal third of the tail was left uncovered, an electrode was applied and about 80 electric shocks ( $1 \mathrm{~mA} \times 5 \mathrm{sec}, 1$ every $30 \mathrm{sec}$ ) were administered. Twenty-four hours later, rats were tested in a shock-escape paradigm in an apparatus consisting of a Plexiglas cage $(30 \times 60 \times 30 \mathrm{~cm})$ with dark walls and a floor fitted with stainless steel rods spaced 1 $\mathrm{cm}$ apart. The cage was divided into two equal chambers (by a dark Plexiglas partition with a $10 \times 10 \mathrm{~cm}$ sliding door), one disconnected from the tail electrode (neutral chamber) and the other connected with it (electrified chamber) through a S 44 Grass stimulator. An electrode was applied to the tail, the animal was placed in the electrified chamber and, after a 5 min habituation period, received 30 consecutive electric shocks ( $1 \mathrm{~mA} \mathrm{x}$ $5 \mathrm{sec})$, at $30 \mathrm{sec}$ intervals. Shocks were delivered in coincidence with a $5 \mathrm{sec}$ opening of the door $(10 \times 10 \mathrm{~cm})$ connecting the electrified chamber to the neutral one. Animals that succeeded in escaping were gently replaced in the electrified chamber, at the end of the $5 \mathrm{sec}$ shock delivery. In our experimental conditions, naive rats (which had not received unavoidable stress) scored between 22 to 30 escapes out of 30 trials. More than $95 \%$ of rats developed an escape deficit state, defined by a score which ranges from 0 to 3 escapes out of 30 trials when tested $24 \mathrm{hr}$ after the unavoidable shock session.

Chronic Stress Procedure. For the chronic stress protocol, a group of rats was initially exposed to the standard sequence of the unavoidable shock session and test trials. Animals were then selected on the basis of their failure to escape (0-3 escapes / 30 trials) and, in order to maintain the escape deficit, each of them:

a- was restrained for $10 \mathrm{~min}$ starting $48 \mathrm{hr}$ after the escape test;

b- received $10 \mathrm{~min}$ of restraint plus 1-4 unavoidable shocks $48 \mathrm{hr}$ after a;

c- spent $20 \mathrm{~min}$ in the cage where the unavoidable shock had previously been administered $48 \mathrm{hr}$ after $\mathrm{b}$.

By repeating this alternate-day-stress-procedure, the escape deficit state could be maintained indefinitely in all animals (De Montis et al. 1995).

\section{Induction of Vanilla Pellet Controlled Appetitive Behavior}

Rats fed freely with a standard diet were used. The procedure utilized has already been described in detail (Ghiglieri et al. 1997) and will be summarized below.

Apparatus. A dark Plexiglas box (box 1: $15 \times 20 \times 20$ $\mathrm{cm}$ ) was separated by a $10 \times 10 \mathrm{~cm}$ sliding door from a similar box (box 2) which constituted the straight arm of a Y-maze ( $15 \times 40 \times 20 \mathrm{~cm}$ for each of the three arms). The apparatus was located in a testing room separated from and adjacent to the main animal room, under the same conditions of light, temperature and humidity. Experiments were carried out under controlled noise conditions. A vanilla pellet was used as reinforcer and was placed at the end of one of the two divergent arms.

Training Procedure. The day before the first training session rats were allowed a first run in the Y-maze with one of the two arms closed. Each animal was placed in box 1 and $10 \mathrm{sec}$ later a $5 \mathrm{sec}$ tone signalled the opening of the sliding door. Animals were given $2 \mathrm{~min}$ to enter box 2 and to reach the end of the open arm where a vanilla pellet (reinforcer) was earned. The time allowed was sufficient for all the animals to earn the reward. The training procedure began $24 \mathrm{hr}$ later according to the following protocol:

During training sessions 1-3, the animal was placed in box 1 and, after $10 \mathrm{sec}$, a 5 ses tone signalled the opening of the sliding door. If the rat did not enter box 2 within $60 \mathrm{sec}$ it was returned to the home cage for 15 min. If it entered box 2 it was allowed $60 \mathrm{~s}$ to reach the end of one of the two diverging arms. Either the right or the left arm was designated correct, balanced across animals. If the empty arm was chosen, the rat was returned to the home cage for $15 \mathrm{~min}$ before the next trial. If the baited arm was chosen the rat was allowed to consume the vanilla pellet and then returned to the home cage for $15 \mathrm{~min}$ before the next trial. The two intervals (time to leave box 1 and time to reach the end of an arm) were progressively reduced throughout training sessions and beginning with session 10 they were fixed at 10 and $20 \mathrm{sec}$, respectively.

Each rat underwent a total of 10 complete trials (one of the two ends reached) for each session, at $15 \mathrm{~min}$ intervals. Training sessions were administered every second day.

Training of Stressed Rats. Naive rats were exposed to the standard procedure of the unavoidable stress session and were tested for escape on the following day. Animals presenting 0-3 escapes/30 trials were chosen and administered the training protocol starting $24 \mathrm{hr}$ later. Each rat in this group received these two procedures alternated daily, for a total of four weeks. 


\section{Experimental Protocols}

Acute Treatments. The purpose of the experiment was the evaluation of the protective effect of the acute administration of $H$. perforatum on the behavioral sequelae of an unavoidable stress, and the identification of the neurotransmitter systems possibly mediating such effect. A first group of 40 rats was divided into the following subgroups:

7 animals received saline $(2 \mathrm{ml} / \mathrm{kg}$, p.o.) before the unavoidable stress session and underwent the escape test $24 \mathrm{hr}$ later;

7 animals received saline $(2 \mathrm{ml} / \mathrm{kg}$, p.o.) and underwent the escape test the following day, without unavoidable stress session (naive);

4 subgroups of 6-8 rats each received $H$. perforatum at the doses of 250, 500, 1000, and $1500 \mathrm{mg} / \mathrm{kg}$, p.o. 60 $\mathrm{min}$ before the inescapable stress and were tested for escape on the following day.

A second group of 30 rats was divided into the following subgroups:

10 rats received a single dose of $H$. perforatum and saline $(1 \mathrm{ml} / \mathrm{kg}), 60$ and $20 \mathrm{~min}$ before the inescapable stress, respectively, and were tested for escape on the following day;

10 rats received a single dose of $H$. perforatum and the $\mathrm{D}_{1}$ dopamine receptor antagonist SCH 23390 (0.03 $\mathrm{mg} / \mathrm{kg}$, s.c.), 60 and $20 \mathrm{~min}$ before the inescapable stress, respectively, and were tested for escape on the following day;

10 rats received a single dose of $H$. perforatum and the $5-\mathrm{HT}_{1 \mathrm{~A}}$ receptor antagonist (-)-pindolol $(5 \mathrm{mg} / \mathrm{kg}$, i.p.), 60 and 20 min before the inescapable stress, respectively, and were tested for escape on the following day.

A third group of 20 animals was divided into 2 subgroups:

10 rats received a single dose of $H$. perforatum and saline $(1 \mathrm{ml} / \mathrm{kg}), 60$ and $20 \mathrm{~min}$ before the inescapable stress, respectively, and were tested for escape on the following day;

10 rats received a single dose of $H$. perforatum and the $5-\mathrm{HT}_{1 \mathrm{~A}}$ receptor antagonist WAY-100635 $(0.1 \mathrm{mg} / \mathrm{kg}$, s.c.), 60 and $20 \mathrm{~min}$ before the inescapable stress, respectively, and were tested for escape on the following day.

Repeated Treatments. The purpose of this experiment was the evaluation of the protective effect of repeatedly administered $H$. perforatum extract on the behavioral sequelae of an unavoidable stress, and the possible neurotransmitter systems mediating such effect. A group of 48 animals was divided as follows:
16 rats were treated with saline $(2 \mathrm{ml} / \mathrm{kg}$, b.i.d.) for 15 days. At the end of treatment, half of the animals were exposed to the unavoidable stress session $24 \mathrm{hr}$ before the escape test (controls) and the other half were tested without stress exposure (naive);

32 rats were divided into 4 subgroups of 8 animals each and treated for 15 days with $H$. perforatum at the doses of 250, 500, and $1000 \mathrm{mg} / \mathrm{kg}$ p.o., b.i.d., respectively, or with imipramine $(5 \mathrm{mg} / \mathrm{kg}$, i.p. b.i.d.). On the $16^{\text {th }}$ day, they were exposed to the unavoidable stress session and $24 \mathrm{hr}$ later to the escape test.

Subsequently, a group of 50 rats was subdivided as follows:

40 animals were treated with $H$. perforatum $1 \mathrm{~g} / \mathrm{kg}$, p.o., b.i.d. for 15 days. On the $16^{\text {th }}$ day, $20 \mathrm{~min}$ before the unavoidable stress, 10 of them received $\mathrm{SCH}$ 23390 ( $0.03 \mathrm{mg} / \mathrm{kg}$, s.c.), 10 were given (-)-pindolol (5 $\mathrm{mg} / \mathrm{kg}$, i.p.), 10 were given propranolol $(5 \mathrm{mg} / \mathrm{kg}$, i.p.), and 10 received saline $(1 \mathrm{ml} / \mathrm{kg}) ; 10$ rats (controls) were treated with saline $(2 \mathrm{ml} / \mathrm{kg}$, b.i.d., p.o.) for the same period of time. On the $16^{\text {th }}$ day, they were exposed to the unavoidable stress session and $24 \mathrm{hr}$ later to the escape test.

\section{H. Perforatum on Chronic ED}

The purpose of this experiment was to investigate whether a treatment with $H$. perforatum could revert the ED maintained by chronic stress. Fifty rats were initially exposed to a whole unavoidable stress session and test trial. Forty of them were then selected on the basis of their failure to escape, and divided into four subgroups of 10 animals each. To maintain the ED condition, during the following three weeks all selected animals underwent the chronic stress protocol described above. Subgroups were treated for three weeks as follows: 1) saline, $0.1 \mathrm{ml} / \mathrm{kg}$ i.p., b.i.d.; 2) $H$. perforatum 1 $\mathrm{g} / \mathrm{kg}$, p.o., b.i.d.; 3) imipramine, $5 \mathrm{mg} / \mathrm{kg}$ i.p., b.i.d.; and 4) fluoxetine, $5 \mathrm{mg} / \mathrm{kg} /$ day, i.p.

\section{H. Perforatum on the Acquisition of Appetitive Behavior}

The purpose of this experiment was to investigate whether a treatment with $H$. perforatum could antagonize the disrupting effect of chronic stress on the acquisition of vanilla pellet controlled appetitive behavior in rats. Treatments with saline $(1 \mathrm{ml} / \mathrm{kg}$, i.p.), H. perforatum (1 g/ $\mathrm{kg}$, p.o., b.i.d.), imipramine (5 $\mathrm{mg} / \mathrm{kg}$, i.p., b.i.d.), or fluoxetine $(5 \mathrm{mg} / \mathrm{kg} /$ day, i.p.) began two weeks before the training procedure and were continued throughout the entire experiment. Rats were divided into six groups according to the following protocol: Two groups of animals received saline (Control) or $H$. perforatum (H. perforatum) for two weeks and then be- 
gan the training protocol while continuing treatment. The remaining four groups of animals were treated daily with saline, imipramine, fluoxetine, or $H$. perforatum for two weeks. On day 14, they received the unavoidable stress session and the escape test on the following day. Animals underwent the double protocol (training under stress) on alternate days as already described, while continuing to receive saline (Stress/saline), imipramine (Stress/imipramine), fluoxetine (Stress/ fluoxetine), or H. perforatum (Stress/H. perforatum).

\section{Locomotor Activity}

The purpose of these experiments was that of evaluating a possible motor stimulant activity of $H$. perforatum, which would constitute a bias in evaluating an escape deficit behavior. Three groups of 10 animals each, treated with saline, $H$. perforatum, or imipramine for 15 days as described above, were tested for locomotor activity after saline and quinpirole administration. Experiments were performed in a sound-proof room, between 10:00 a.m. and 5:00 p.m. Rats were individually placed in locomotor activity cages (M/P40 Fc Electronic Motility Meter, Motor Products, Stockholm). Each cage had 40 photo-conductive sensors placed in the floor area $(21 \times 32 \mathrm{~cm})$ at a fixed distance of $4 \mathrm{~cm}$. These sensors and the arena were uniformly illuminated by an incandescent lamp mounted $60 \mathrm{~cm}$ above the floor. Motor activity was defined as the number of interruptions of a beam during a $30 \mathrm{~min}$ observation period. During the last 5 days of treatment animals were placed in the motility cage for $15 \mathrm{~min} /$ day. On day 15, one hour after the last treatment, rats were injected with saline and observed for $30 \mathrm{~min}$ after a $10 \mathrm{~min}$ habituation period. Motility counts were recorded, then the $D_{2} / D_{3}$ dopam- ine agonist quinpirole was administered at the dose of $0.25 \mathrm{mg} / \mathrm{kg}$, s.c., and rats were observed for 30 additional min.

\section{Drugs}

Imipramine, fluoxetine, SCH 23390, d,l-propranolol, WAY100135, and quinpirole were dissolved in $0.9 \%$ saline. (-)-Pindolol was dissolved in a few drops of glacial acetic acid and brought to volume with $0.9 \%$ saline, the $\mathrm{pH}$ was adjusted to 6-6.5 with a Tris $\mathrm{HCl}$ saturated solution. The injected volume for all of these compounds was $0.1 \mathrm{ml} / 100 \mathrm{~g}$ rat body weight. A dry hydro-alcoholic extract of $H$. perforatum $(0.3 \%$ hypericin content) was mixed with methyl-cellulose $(1: 0.04)$ and a suspension was prepared daily with water to a final volume of $0.2 \mathrm{ml} / 100 \mathrm{~g}$ body weight. Each drug treated group had its proper controls which received the corresponding volume of the appropriate vehicle by the same route of administration. Imipramine, SCH 23390, (-)-pindolol, d,l-propranolol, quinpirole, and WAY100635 were purchased from commercial sources; $H$. perforatum extract was generously supplied by Indena S.p.A., Italy; fluoxetine was a gift from Eli Lilly, U.S.A.

\section{Statistics}

All data are expressed as mean \pm S.E.M. Since multiple drug treatments were compared with values from a single control group, statistical comparisons were made by nonparametric ANOVA test (Kruskal-Wallis) followed by "post hoc" analysis using the Dunn's multiple comparison test (Instat 2.01 for Macintosh, GraphPad Software, Inc.), unless otherwise specified.

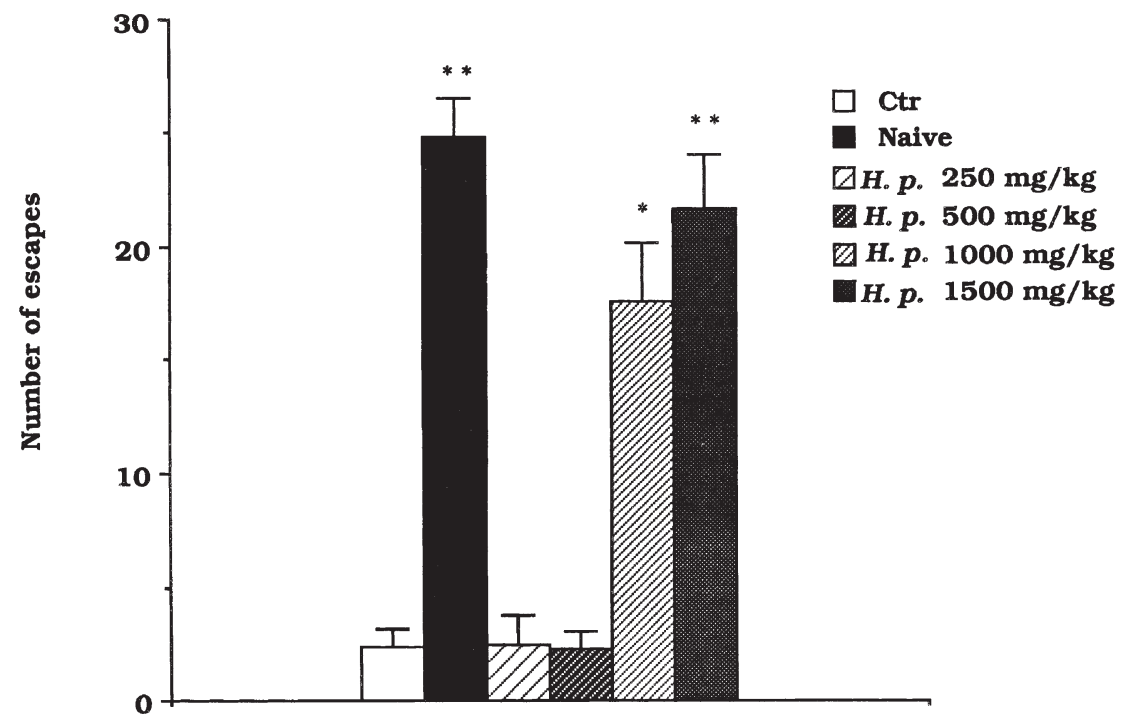

Figure 1. Effect of acute treatment with $H$. perforatum on ED acquisition by rats. Animals received 4 different doses of the extract (H. p.) $(250,500,1000$, and 1500 $\mathrm{mg} / \mathrm{kg}$ ) or saline (Ctr), p.o. $60 \mathrm{~min}$ before the unavoidable shock session. Scores are expressed as average number of escapes \pm S.E.M. in 30 consecutive trials; $n=7$ for Ctr and Naive groups; 6 for $H$. p. 250, 500, and $1500 \mathrm{mg} / \mathrm{kg}$ groups; 8 for H. p. $1000 \mathrm{mg} / \mathrm{kg}$ group. *Significantly different from Ctr animals $(p<.05)$. **Significantly different from Ctr animals $(p<.01)$. 


\section{RESULTS}

\section{Effect of Acute H. Perforatum Administration on ED Acquisition}

The effect of an acute treatment with different doses of $H$. perforatum on ED acquisition by rats was initially examined. Animals received 250, 500, 1000, or $1500 \mathrm{mg} /$ $\mathrm{kg}$ of total extract or saline p.o. $60 \mathrm{~min}$ before the inescapable shock session, and $24 \mathrm{hr}$ later they were tested for escape. Analysis of the data by non parametric Kruskal-Wallis test demonstrated a significant difference among groups (KW $=30.295, p<.001)$; post-hoc analysis showed that the score of naive rats and of $H$. perforatum 1 and $1.5 \mathrm{~g} / \mathrm{kg}$ treated rats was significantly different from the score of control animals $(p<.01, p<$ .05 , and $p<.01$, respectively) (Figure 1 ).

To exclude a non-specific analgesic effect of the extract on the escape test, two groups of 10 rats each were tested with the radiant heat tail-flick or the hot-plate method. Following base-line assessment, rats were administered $H$. perforatum $(1 \mathrm{~g} / \mathrm{kg}$, p.o.) one hour before the test session; the session was repeated one hour later. In the tail-flick test none of the animals showed a higher, or in anyway modified, pain threshold at both time intervals after $H$. perforatum administration (baseline value: $5.7 \pm 0.2 \mathrm{sec}$; $1 \mathrm{hr}$ after $H$. perforatum: $5.7 \pm$ $0.2 \mathrm{sec} ; 2 \mathrm{hr}$ after $H$. perforatum: $5.3 \pm 0.4 \mathrm{sec})$. Similar results were obtained with the hot-plate test: baseline value: $4.4 \pm 0.3 \mathrm{sec} ; 1-2 \mathrm{hr}$ after $H$. perforatum: $4.7 \pm 0.2 \mathrm{sec}$.

To verify whether the observed protective effect was related to a prominent function of dopamine $\mathrm{D}_{1}$ or/and $5-\mathrm{HT}_{1 \mathrm{~A}}$ serotonin receptor systems, animals received $H$. perforatum extract $(1 \mathrm{~g} / \mathrm{kg}$, p.o.) $60 \mathrm{~min}$ before the unavoidable stress, and $40 \mathrm{~min}$ later SCH 23390 or (-)-pindolol was administered. Nonparametric analysis of variance revealed that a significant difference existed among the groups (KW $=18.55, p<.001)$. In fact, Figure 2 shows that the protective activity of the extract at the dose of 1 $\mathrm{g} / \mathrm{kg}$ was significantly reduced by both SCH 23390 and (-)-pindolol ( $p<.001$ and $p<.01$, respectively; Dunn's test). Results similar to those obtained with $(-)$-pindolol were observed when WAY-100635 (0.1 mg/ $\mathrm{kg}$, s.c.) was administerd 40 min after $H$. perforatum extract $(1 \mathrm{~g} / \mathrm{kg}$, p.o.) and $20 \mathrm{~min}$ before the unavoidable stress $(\mathrm{H}$. perforatum treated animals: $17.6 \pm 0.7$ escapes versus $H$. perforatum + WAY-100635: $2.1 \pm 0.7$ escapes, $p<.001$; unpaired t-test).

\section{Effect of Repeated Administration of $\boldsymbol{H}$. Perforatum on ED Acquisition}

The effect of long-term $H$. perforatum administration was then studied. Different doses of a suspension of the extract or saline were administered to rats p.o., b.i.d. for 15 days. Figure 3 shows that the effect of the dose of $H$. perforatum already active after acute administration did not decline upon repeated daily doses; indeed, the number of escapes after 15 days of treatment was higher than that recorded after a single administration. Moreover, the $500 \mathrm{mg} / \mathrm{kg}$ dose induced a protective effect, albeit of a lesser degree than the $1 \mathrm{~g} / \mathrm{kg}$ dose. Furthermore, the figure shows that the effect of $H$. perforatum $(1 \mathrm{~g} / \mathrm{kg})$ on the ED paradigm was similar to that induced by the treatment of rats with imipramine for 15 days. One-way analysis of variance demonstrated a significant difference among the groups $\left(\mathrm{F}_{39,44}=175.12\right.$, $p<.001$ ); post-hoc analysis (Dunnett multiple comparison test) revealed the existence of a significant difference between naive and control group performance $(p<.01)$, between control and imipramine $(p<.01)$, and between control and H. perforatum $1 \mathrm{~g} / \mathrm{kg}(p<.01)$ and $500 \mathrm{mg} / \mathrm{kg}(p<.05)$.

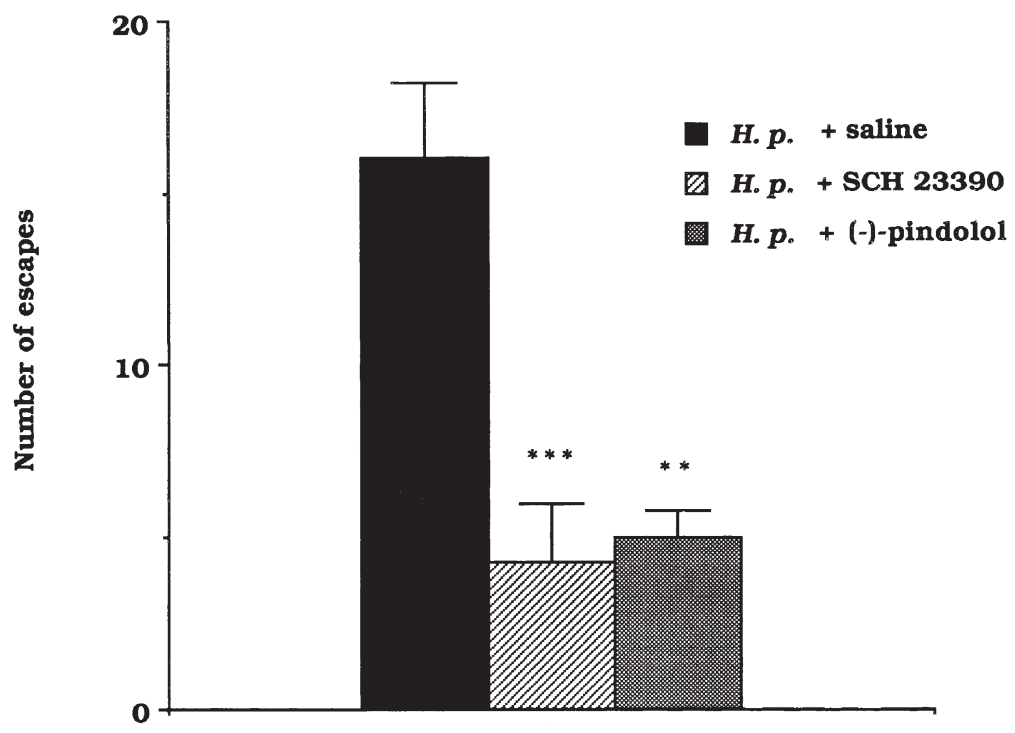

Figure 2. The acute administration of a $D_{1}$ dopamine receptor or a $5-\mathrm{HT}_{1 \mathrm{~A}}$ receptor antagonist significantly prevented the protective effect of $H$. perforatum on ED acquisition by rats. Animals received $H$. perforatum $(1 \mathrm{~g} / \mathrm{kg})$ $60 \mathrm{~min}$ before the unavoidable shock session. Twenty min before the unavoidable stress, saline, SCH 23390 (0.03 mg/kg, s.c.), or (-)-pindolol ( $5 \mathrm{mg} / \mathrm{kg}$, i.p.) were administered. Scores are expressed as average number of escapes \pm S.E.M. in 30 consecutive trials; $n=10$ for each group. ${ }^{*}$ Significantly different from $H . p .+$ saline animals $(p<.01)$. ${ }^{* *}$ Significantly different from H. $p$. + saline animals $(p<.001)$. 


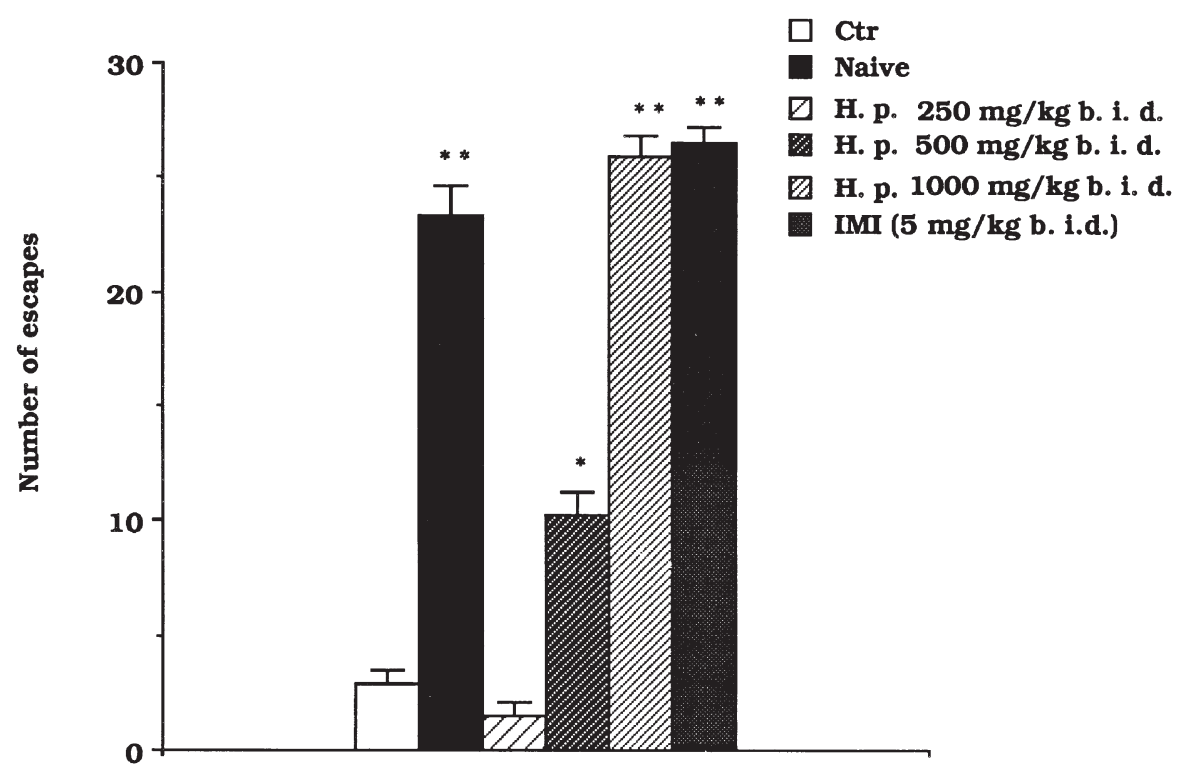

Figure 3. The repeated treatment with $H$. perforatum prevents ED induction in rats. Saline (Ctr), imipramine (IMI), or different doses of H. perforatum extract (H. p.) $(250,500$, $1000 \mathrm{mg} / \mathrm{kg}$ ) were administered to rats twice a day for 15 days. On the $16^{\text {th }}$ day, animals underwent the unavoidable stress session; half of the saline treated rats did not undergo the unavoidable stress session (Naive). Scores are expressed as average number of escapes \pm S.E.M. in 30 consecutive trials; $n=8$ for each group. *Significantly different from Ctr animals $(p<.05)$. ${ }^{*}$ Significantly different from Ctr animals $(p<.01)$.

A potential analgesic activity was also assessed after a 15 day treatment with different doses of $H$. perforatum, 14-16 hr after the last drug administration, by the hotplate test. No significant difference in mean latency time was observed between control rats and animals treated with $H$. perforatum (control group: $4.7 \pm 0.3 \mathrm{sec}$; H. perforatum $250 \mathrm{mg} / \mathrm{kg}$ : $4.8 \pm 0.2 \mathrm{sec} ;$ H. perforatum 500 $\mathrm{mg} / \mathrm{kg}: 5.2 \pm 0.2 \mathrm{sec}$; $H$. perforatum $1 \mathrm{~g} / \mathrm{kg}: 5.8 \pm 0.1$ $\mathrm{sec})$. To ascertain whether the activity of $H$. perforatum extract on ED was related to a non-specific activating effect, spontaneous locomotor activity was monitored in rats which had received the extract $(1 \mathrm{~g} / \mathrm{kg})$ or saline $(2$ $\mathrm{ml} / \mathrm{kg}$ ) p.o., b.i.d. for a period of 15 days. Analysis of the data reported in Table 1 showed a statistical difference among groups (one-way ANOVA, $\mathrm{F}_{7,80}=37.438, p<$ .001); post-hoc analysis revealed that repeated $H$. perforatum administration reduced spontaneous motor activity in rats one hour after the last treatment, as compared to control rats ( $p<.01$; Bonferroni's test). Moreover, H. perforatum and saline-treated rats did not increase their locomotor activity in response to the administration of the $\mathrm{D}_{2} / \mathrm{D}_{3}$ dopaminergic agonist quinpirole. Whereas, imipramine-treated animals, which did not show a basal locomotor activity different from that of controls, showed significantly increased motility after quinpirole administration ( $p<.001$; Bonferroni's test) (Table 1$)$.

Finally, the possible role played by $\mathrm{D}_{1}$ dopamine or $5-\mathrm{HT}_{1 \mathrm{~A}}$ receptor systems in the ED protective effect of a chronic treatment with $H$. perforatum was studied. The extract was administered to rats p.o. twice a day for 15 days; 20 min before the inescapable stress, four subgroups of 10 rats each received saline, SCH 23390, (-)-pindolol or propranolol. Statistical analysis of the data demonstrated a significant difference among groups $(\mathrm{KW}=39.935, p<.001)$. In particular, post-hoc analysis (Dunn's test) confirmed that rats receiving saline for 15 days showed a significantly different number of escapes compared to $H$. perforatum treated animals $(p<.001)$. Moreover, it revealed that rats treated with either $\mathrm{SCH}$ 23390 or (-)-pindolol showed a significantly reduced number of escapes compared to $H$. perforatum treated animals receiving acute saline $(p<.01$ and $p<.001$, respectively), while propranolol had no effect $(p>$.05) (Figure 4$)$.

\section{Effect of $H$. Perforatum on Chronic ED}

In another set of experiments we studied the reversal of the ED state on chronically stressed rats by H. perforatum treatment. Animals, chosen on the basis of their ED intensity $24 \mathrm{hr}$ after the unavoidable shock session, underwent the chronic stress procedure with or without a concomitant pharmacological treatment. Table 2 shows that after three weeks of repeated stress saline treated

Table 1. Locomotor Activity of Rats Treated with Saline, H. Perforatum or Imipramine for 15 Days

\begin{tabular}{llc}
\hline & \multicolumn{2}{c}{ Motility counts (30 min) } \\
\cline { 2 - 3 } Group & Saline & Quinpirole \\
\hline Saline & $2377 \pm 245$ & $2236 \pm 208$ \\
H. perforatum & $1575 \pm 185^{\mathrm{a}}$ & $1630 \pm 140$ \\
Imipramine & $1940 \pm 133$ & $4590 \pm 203^{\mathrm{b}}$
\end{tabular}

Values are the mean \pm S.E.M. of motility counts of 10 animals for each group. Animals were observed for spontaneous locomotor activity $1 \mathrm{hr}$ after their daily treatment with saline, $H$. perforatum $(1 \mathrm{~g} / \mathrm{kg}$, b.i.d.) or imipramine ( $5 \mathrm{mg} / \mathrm{kg}$, b.i.d.). Thirty min later, quinpirole $(0.25 \mathrm{mg} / \mathrm{kg}$, s.c.) was administered to both groups of rats and locomotor activity during the following $30 \mathrm{~min}$ was recorded.

aSignificantly different from spontaneous locomotor activity of Saline rats ( $p<.01$, ANOVA plus post-hoc Bonferroni's test).

bSignificantly different from locomotor activity of Saline rats after quinpirole administration $(p<.001$, ANOVA plus post-hoc Bonferroni's test). 


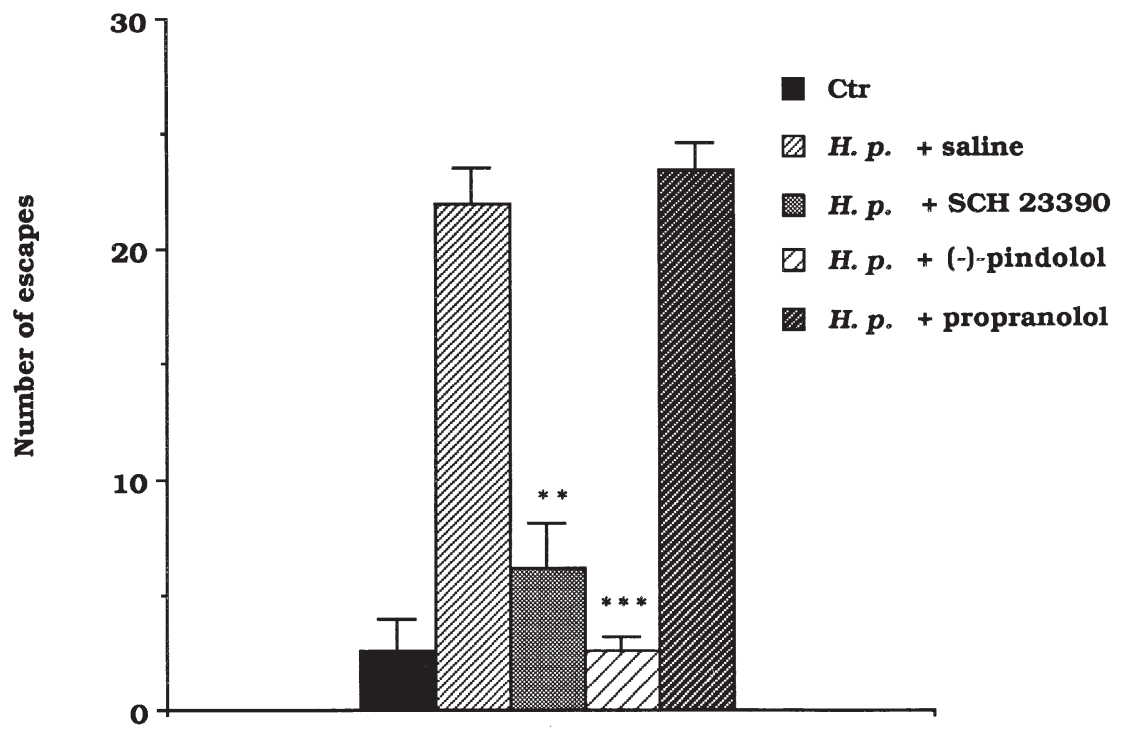

Figure 4. The effect of chronic treatment with $H$. perforatum on ED development is prevented by the inhibition of either $\mathrm{D}_{1}$ dopamine or $5-\mathrm{HT}_{1 \mathrm{~A}}$ receptors. The extract of $H$. perforatum $(1 \mathrm{~g} / \mathrm{kg})$ was administered to rats p.o. twice a day for 15 days. Twenty min before the pre-test, animals were divided in four groups of 10 rats each that received either $\mathrm{SCH}$ 23390 (0.03 mg/kg, s.c.), (-)-pindolol (5 $\mathrm{mg} / \mathrm{kg}$, i.p.), propranolol (5 mg/kg, i.p.), or saline. Scores are expressed as average number of escapes \pm S.E.M. in 30 consecutive trials; $n=10$ for each group. **Significantly different from $H$. $p$. rats $(p<.01){ }^{* * * \text { Significantly different from }}$ H. $p$. rats $(p<.001)$. rats performed an average of 1.2 escapes out of 30 trials. $H$. perforatum administered twice a day at a dose of $1 \mathrm{~g} /$ $\mathrm{kg}$ completely reverted the ED state, with an efficacy similar to that of imipramine or fluoxetine. The statistical analysis of the number of escapes showed a significant difference among group scores $(\mathrm{KW}=53.616, p<$ .001). Post-hoc analysis (Dunn's test) demonstrated no statistical differences among the basal scores of all groups of animals, while there was a significant difference between the saline treated group compared to the groups treated with imipramine $(p<.01)$, fluoxetine $(p<.01)$, and H. perforatum $(p<.001)$.

\section{Effect of H. Perforatum on Stress-Disrupted Appetitive Behavior}

Chronic stress prevents the acquisition by rats of an operant appetitive behavior induced by a palatable food
(Ghiglieri et al. 1997). Thus, the possibility that $H$. perforatum would protect animals from the stress-induced decreased motivation was studied. Animals underwent the unavoidable stress session and started training on the Y-maze while undergoing the chronic stress procedure, with or without a concomitant pharmacological treatment. A control group was trained in parallel. Oneway analysis of variance of the data shown in Table 3 demonstrated a significant difference among groups $\left(\mathrm{F}_{5,69}=15.238\right)$. Post-hoc analysis of the number of correct trials (Bonferroni's test) showed that chronic stress prevented the acquisition of the appetitive behavior ( $p<.001$ stress/saline versus control group), and that $H$. perforatum treatment was as potent as imipramine or fluoxetine treatments in protecting rats from the disrupting effect of stress $(p<.001$ stress $/ H$. perforatum, stress/imipramine, stress/fluoxetine versus stress/saline group).

Table 2. The Effect of H. P. Repeated Treatment on Chronic ED

\begin{tabular}{lcc}
\hline & \multicolumn{2}{c}{ Number of escapes } \\
\cline { 2 - 3 } Group & Basal value & After a 3 Week Stress Protocol + Treatment \\
\hline Saline & $1.8 \pm 0.6$ & $1.2 \pm 0.5$ \\
Imipramine & $1.4 \pm 0.5$ & $21.2 \pm 2.3^{\mathrm{a}}$ \\
Fluoxetine & $1.4 \pm 0.5$ & $22.7 \pm 1.3^{\mathrm{a}}$ \\
H. perforatum & $2.4 \pm 0.8$ & $23.4 \pm 1.9^{\mathrm{b}}$ \\
\hline
\end{tabular}

Values are the mean \pm S.E.M. of number of escapes of 10 animals for each group. Animals were tested for escape $24 \mathrm{hr}$ after the exposure to a single session of inescapable shock (Basal value) and after three weeks of stress protocol plus daily treatment with saline, imipramine $(5 \mathrm{mg} / \mathrm{kg}$. b.i.d.), fluoxetine $(5 \mathrm{mg} / \mathrm{kg} /$ day $)$ or H. perforatum (lg $/ \mathrm{kg}$, b.i.d.), as described in Methods.

aSignificantly different from number of escape of Saline rats $(p<.01)$

${ }^{b}$ Significantly different from number of escape of Saline rats $(p<.001)$. 
Table 3. The Effect of Repeated Treatment with Imipramine, Fluoxetine, or H. Perforatum on the Acquisition of Vanilla Pellet Controlled Appetitive Behavior in Control and Chronically Stressed Rats

\begin{tabular}{lrc}
\hline Group & $\boldsymbol{n}$ & Correct Trials \\
\hline Control & 10 & $7.7 \pm 0.7$ \\
Control/H. perforatum & 7 & $6.2 \pm 0.9$ \\
Stress/saline & 10 & $2.6 \pm 0.5^{\mathrm{a}}$ \\
Stress/imipramine & 16 & $7.3 \pm 0.4^{\mathrm{b}}$ \\
Stress/fluoxetine & 16 & $6.8 \pm 0.5^{\mathrm{b}}$ \\
Stress/H. perforatum & 16 & $8.0 \pm 0.4^{\mathrm{b}}$ \\
\hline
\end{tabular}

Values are the mean \pm S.E.M. of the 10 trials of test session. Animals were tested for vanilla pellet controlled appetitive behavior after training under control conditions or exposure to a chronic stress protocol plus daily treatment with saline, imipramine $(5 \mathrm{mg} / \mathrm{kg}$, b.i.d.), fluoxetine ( 5 $\mathrm{mg} / \mathrm{kg} /$ day) or Hypericum perforatum $(1 \mathrm{~g} / \mathrm{kg}$, b.i.d.), as described in Methods.

aSignificantly different from Control rats $(p<.001$, Bonferroni's test). bSignificantly different from Stress/saline rats $(p<.001$, Bonferroni's test).

\section{DISCUSSION}

$H$. perforatum, given acutely at doses of $1-1.5 \mathrm{~g} / \mathrm{kg}$ one hour before the unavoidable shock session, significantly increased the animals' endurance to noxious stimuli, and this protective effect was retained and enhanced in rats treated b.i.d. for 15 consecutive days. The efficacy of $H$. perforatum was similar to that of imipramine (5 $\mathrm{mg} / \mathrm{kg}$ i.p., b i.d., for 15 days). Moreover, the effect of $H$. perforatum on the ED paradigm was not related to a non-specific increase in locomotor activity. In fact, motility was lower in the treated animals, as compared to control rats, and a prior experiment with the tail-flick and the hot-plate tests excluded the possible analgesic activity of the extract. The $500 \mathrm{mg} / \mathrm{kg}$ b.i.d. dose, which was not effective in the acute experiment, significantly protected rats after long-term treatment, although the maximum effect was observed with $1 \mathrm{~g} / \mathrm{kg}$ b.i.d. The 1 $\mathrm{g} / \mathrm{kg}$ b.i.d dose was then used in ED reversal experiments, as well as during the acquisition phase of appetitive operant behavior in stressed rats. $H$. perforatum showed an efficacy similar to that of chronic imipramine or fluoxetine in both these conditions.

The following details and comments on the models used have been included in order to better evaluate the observed behavioral effects of $H$. perforatum:

First, acute ED is a simplified version of the classical learned helplessness syndrome (Overmier and Seligman 1967; Seligman and Maier 1967; Sherman et al. 1982). During the four days preceding the escape test each animal is allowed a daily $10 \mathrm{~min}$ period of exploration in the experimental cage with the sliding door open, because familiarity with the environment greatly improves an animal's performance. In fact, in our experimental conditions more than $90 \%$ of non-stressed rats accom- plish an average of 26 escapes out of 30 trials. Immobilization strengthens the unavoidability of the relatively mild tail shocks, and in more than $90 \%$ of stressed rats the number of escapes is reduced to an average of 1-3 out of 30 trials. We define this model of ED as acute because the time interval between the unavoidable stress and the escape test cannot be delayed beyond $24 \mathrm{hr}$, in order to observe a significant hyporeactivity in $90 \%$ of the animals. This interval is too short for the evaluation of ED reversal, since classical antidepressants require at least 4-6 days of continuous treatment to become active (Sherman et al. 1982). Thus, the utilization of acute ED has been restricted to the assessment of the prevention liability of potential antidepressant treatments on the behavioral sequelae of stress (Gambarana et al. 1995a). Acute ED is also an appropriate tool for the study of the effects of agonists and antagonists, specific for different receptor types, on the protective activity of antidepressant treatments. Accordingly, it was demonstrated that the action of imipramine on ED development is mediated by selective $D_{1}$ dopamine receptor activation. In fact, the protective effect of a three-week daily treatment with imipramine was blocked by the administration of SCH 23390 and mimicked by an acute injection of SKF 38393 carried out shortly before the unavoidable stress session, whereas $\mathrm{D}_{2}$ dopamine receptor inhibition failed to modify imipramine efficacy (Gambarana et al. 1995b). Moreover, the protective effect of long-term fluoxetine is only slightly inhibited by SCH 23390 , it is mimicked by 8-OH-DPAT, a selective $5-\mathrm{HT}_{1 \mathrm{~A}}$ receptor agonist, and it is cancelled by (-)-pindolol (Gambarana et al. 1995a, Gambarana et al. unpublished observations). Pindolol also blocks the protective effect of 8-OH-DPAT in the forced swim test (Detke et al. 1995). The antidepressant activity of $H$. perforatum showed the same sensitivity to the administration of SCH 23390 after both acute and repeated treatment. An analogous antagonism was produced by (-)-pindolol, a $\beta$-adrenergic receptor blocker with potent activity at $5-\mathrm{HT}_{1 \mathrm{~A}}$ receptors as an antagonist or weak partial agonist (Hamon et al. 1990). This effect cannot be ascribed to $\beta$-adrenoceptor blockade, since propranolol failed to reproduce it. On the other hand, pindolol and propranolol are potent, non selective inhibitors of 5- $\mathrm{HT}_{1 \mathrm{~A}}$ and $5-\mathrm{HT}_{1 \mathrm{~B}}$ receptors (Hamon et al. 1990, Middlemiss and Hutson 1990). However, the two compounds seem to differ in their effects upon the serotonergic system. In fact, electrophysiological evidence indicates that propranolol inhibits the stimulation of $5-\mathrm{HT}_{1 \mathrm{~A}}$ receptors induced by $8-\mathrm{OH}-\mathrm{DPAT}$, while it is almost ineffective in antagonizing 5-HT effects (Sprouse and Aghajanian 1986). In addition, the selective silent 5- $\mathrm{HT}_{1 \mathrm{~A}}$ receptor antagonist WAY 100635 (Forster et al. 1995) completly antagonized the protective effect of acute $H$. perforatum. Thus, $H$. perforatum appeared to act through the concurrent stimulation of both dopamine and serotonin receptor systems. Interestingly, repeated 
treatment with $H$. perforatum did not elicit super-sensitivity to quinpirole administration, as opposed to chronic imipramine treatment (Serra et al. 1990), and analogous to long-term fluoxetine and clomipramine treatments (Gambarana et al. 1995c).

Second, the chronic ED condition, as maintained by the repeated stress paradigm, can be used to evaluate the revertant efficacy of a treatment (De Montis et al. 1995). However, chronic ED is less reliable than the acute model for studying the mechanism of a drug's action by the use of selective receptor antagonists, because the effect of any antagonist administered acutely before the last stress session would be difficult to interpret. Moreover, an acute variation produced by any drug on performance during the escape test could hardly be related to a specific antidepressant activity. Any dopamine agonist or central stimulant is able to mobilize ED rats during the escape test (Gambarana et al. 1995c). $H$. perforatum extract showed the same efficacy as imipramine and fluoxetine in reverting chronic ED.

Third, the chronic stress-induced impairment of the acquisition of a goal-seeking behavior aimed at consuming a palatable food has been interpreted as a model of loss of interest, or of anhedonia (loss of pleasure) (Ghiglieri et al. 1997). This model of anhedonia (i.e., of a core symptom of depression) was devised by exploiting the response on a Y-maze maintained by a highly palatable food (vanilla sugar) in rats freely fed on a standard diet (Ghiglieri et al. 1997). Animals exposed to repeated unavoidable stressors during the training phase on the Y-maze did not develop the operant appetitive behavior, and this effect was completely antagonized by imipramine or fluoxetine given daily for two weeks before, as well as during, the training phase (Ghiglieri et al. 1997). H. perforatum showed the same efficacy of imipramine or fluoxetine in protecting rats from the reduced motivation for vanilla sugar induced by chronic exposure to unavoidable stress.

$H$. perforatum seems to be the first drug to show an acute, protective effect on ED development which is maintained upon repeated administration. In fact, classical antidepressants such as imipramine and fluoxetine need to be administered for at least 15 days before their effect becomes significant in this model (Gambarana et al. 1995a). On the other hand, compounds such as SKF 38393, a selective $\mathrm{D}_{1}$ dopamine receptor agonist, or 8-OH-DPAT, a selective $5-\mathrm{HT}_{1 \mathrm{~A}}$ receptor agonist, which acutely protect animals from the sequelae of an unavoidable stress, induce complete tolerance to their initial effect and, after 1-2 weeks of daily administration, treated rats appear hyporeactive to avoidable noxious stimuli (Gambarana et al. 1995c; Gambarana et al. unpublished results).

It may be concluded that the hydro-alcoholic extract of $H$. perforatum used appears to contain some active principle(s) endowed with a potent antidepressant activity which has (have) the ability to prevent the behavioral sequelae of unavoidable stress after a single, or repeated administration. The acute protective effect does not appear to coincide with a rapid onset efficacy in clinical practice (Volz 1997). The antidepressant activity observed after repeated treatment with the extract in our models is in agreement with the results obtained by others with the Porsolt test (Okpanyi and Weischer 1987; Winterhoff et al. 1995; Butterweck et al. 1997) or with the learned helplessness model (Chatterjee et al. 1998). The mechanisms involved in such an effect seem to imply the concurrent activation of the dopaminergic and the serotonergic systems. Such active principle(s) is (are) still unknown, and the present results would suggest the importance of achieving their purification. Moreover, our data suggests that the uncontrolled use of food integrators containing $H$. perforatum extracts should be discouraged because the untitrated active principle could reach doses with unpredictable pharmacological and toxic effects.

\section{ACKNOWLEDGMENTS}

This work was supported by grants from the M.U.R.S.T., ex$60 \%$ and ex- $40 \%$.

\section{REFERENCES}

Bombardelli E, Morazzoni P (1995): Hypericum perforatum. Fitoterapia 66:43-68

Butterweck V, Wall A, Liefländer-Wulf U, Winterhoff H, Nahrstedt A (1997): Effects of the total extract and fractions of hypericum perforatum in animal assays for antidepressant activity. Pharmacopsychiatry 30(Suppl): 117-124

Chatterjee SS, Bhattacharya SK, Wonnemann M, Singer A, Müller WE (1998): Hyperforin as a possible antidepressant component of Hypericum extracts. Life Sci 63:499-510

D'Amour FE, Smith DL (1941): A method for determining loss of pain sensation. J Pharmacol Exp Ther 72:74-79

De Montis MG, Gambarana C, Ghiglieri O, Tagliamonte A (1995): Reversal of stable behavioural modifications through NMDA receptor inhibition in rats. Behav Pharmacol 6:562-567

De Smet PAGM, Nolen WA (1996): St John's wort as an antidepressant. Brit Med J 313:241-242

Detke MJ, Wieland S, Lucki I (1995): Blockade of the antidepressant-like effects of 8-OH-DPAT, buspirone and desipramine in the rat forced swim test by $5-\mathrm{HT}_{1 \mathrm{~A}}$ receptor antagonists. Psychopharmacology 119:47-54

Duke JA (1985) Handbook of Medicinal Herbs. Boca Raton, Florida, CRC Press, pp 242-243

Eddy NB, Leimbach D (1953): Synthetic analgesics. II Diethinylbutenyl- and dithienylbutylamines. J Pharmacol Exp Ther 107:385-393

Erdelmeier CAJ (1998): Hyperforin, possibly the major nonnitrogenous secondary metabolite of Hypericum perforatum L. Pharmacopsychiatry 31:2-6 
Ernst E (1995): St. John's wort, an antidepressant? A systematic, criteria-based review. Phytomedicine 2:67-71

Forster EA, Cliffe IA, Bill DJ, Dover GM, Jones D, Reilly J, Fletcher A (1995): A pharmacological profile of the selective silent $5-\mathrm{HT}_{1 \mathrm{~A}}$ receptor antagonist, WAY100635. Eur J Pharmacol 281:81-88

Gambarana C, Ghiglieri O, Taddei I, Tagliamonte A, De Montis MG (1995a): Imipramine and fluoxetine prevent the stress-induced escape deficits in rats through a distinct mechanism of action. Behav Pharmacol 6:66-73

Gambarana C, Ghiglieri O, Tagliamonte A, D'Alessandro N, De Montis MG (1995b): Crucial role of $\mathrm{D}_{1}$ dopamine receptors in mediating the antidepressant effect of imipramine. Pharmacol Biochem Behav 50:147-151

Gambarana C, Ghiglieri O, De Montis MG (1995c): Desensitization of the $\mathrm{D}_{1}$ dopamine receptors in rats reproduces a model of escape deficit reverted by imipramine, fluoxetine and clomipramine. Prog Neuro-Psychopharmacol Biol Psychiat 19:741-755

Ghiglieri O, Gambarana C, Scheggi S, Tagliamonte A, Willner P, De Montis MG (1997): Palatable food induces an appetitive behaviour in satiated rats which can be inhibited by chronic stress. Behav Pharmacol 8:619-628

Hamon M, Gozlan H, El Mestikawy S, Emerit M.B, Bolaños F, Schechter L (1990): The central 5- $\mathrm{HT}_{1 \mathrm{~A}}$ receptors: Pharmacological, biochemical, functional and regulatory properties. In Whitaker-Azmitia PM, Peroutka SJ (eds), The Neuropharmacology of Serotonin. New York, NY, New York Academy of Science, pp 114-129

Laakmann G, Schüle C, Baghai T, Kieser M (1998): St. John's wort in mild to moderate depression: the relevance of hyperforin for the clinical efficacy. Pharmacopsychiatry 31(Suppl):54-59

Linde K, Ramirez G, Mulrow CD, Pauls A, Weidenhammer W, Melchart D (1996): St John's wort for depression-an overview and meta-analysis of randomised clinical trials. Brit Med J 313:253-258

Middlemiss DN, Hutson PH (1990): The 5- $\mathrm{HT}_{1 \mathrm{~B}}$ receptor. In Whitaker-Azmitia PM, Peroutka SJ (eds), The Neuropharmacology of Serotonin. New York, NY, New York Academy of Science, pp 132-147

Müller WE, Rolli M, Schäfer C, Hafner U (1997): Effects of
Hypericum extract (Li160) in biochemicals models of antidepressant activity. Pharmacopsychiatry 30(Suppl 2):102-107

Müller WE, Singer A, Wonnemann M, Hafner U, Rolli M, Schäfer C (1998): Hyperforin represents the neurotransmitter reuptake inhibiting constituent of Hypericum extract. Pharmacopsychiatry 31(Suppl 1):16-21

Nahrstedt A, Butterweck V (1997): Biologically active and other chemical constituents of the herb of Hypericum perforatum L. Pharmacopsychiatry 30(Suppl 2):129-134

Okpanyi SN, Weischer ML (1987): Tierexperimentelle Untersuchengen zur psychotropen Wirksamkeit eines Hypericum-Extraktes. Arzneimittelforschung 37:10-13

Overmier JB, Seligman MEP (1967): Effects of inescapable shock upon subsequent escape and avoidance learning. J Comp Physiol Psychol 63:23-33

Seligman MEP, Maier SF (1967): Failure to escape traumatic shock. J Exp Psychol 74:1-9

Serra G, Collu M, D’Aquila PS, De Montis MG, Gessa GL (1990): Possible role of dopamine $D_{1}$ receptor in the behavioural supersensitivity to dopamine agonists induced by chronic treatment with antidepressants. Brain Res 527:234-243

Sherman AD, Sacquitine JL, Petty F (1982): Specificity of the learned helplessnes model of depression. Pharmacol Biochem Behav 16:449-454

Sprouse JS, Aghajanian JK (1986): (-)- Propranolol blocks the inhibition of serotonergic dorsal raphe cell firing by $5-\mathrm{HT}_{1 \mathrm{~A}}$ selective agonists. Eur J Pharmacol 125:295-298

Volz HP (1997): Controlled clinical trials of hypericum extracts in depressed patients - an overview. Pharmacopsychiatry 30 (Suppl.): 72-77

Winterhoff H, Butterweck V, Nahrstedt A, Gumbinger HG, Schulz V, Erping S, Boáhammer F, Wieligmann A (1995): Pharmakologische Untersuchungen zur antidepressiven Wirkung von Hypericum perforatum L. In Loew D, Rietbroek N (eds), Phytopharmaka in Forschung und klinischer Anwendung. Steinkopff Verlag, Darmstadt, pp 39-56

Woolfe G, McDonald AD (1944): The evaluation of the analgesic action of pethidine hydrochloride (Demerol). J Pharmacol Exp Ther 80:300-307 